\title{
Effect of Terrain Configuration on the Performance of SRTMv3 and ALOS PALSAR DEMs Over the Federal Capital Territory (FCT), Nigeria.
}

\author{
Charity Olla ${ }^{1}$, Joel Igbokwe ${ }^{2}$, Johnbosco Ojiako ${ }^{2} \&$ Esomchukwu Igbokwe ${ }^{2 *}$ \\ 1. Department of Survey and Mapping, \\ Federal Capital Development Agency (FCDA) Abuja, Nigeria \\ 2. Department of Surveying and Geoinformatics, \\ Nnamdi Azikiwe University, Awka, Anambra State, Nigeria \\ *Corresponding author email: igbokweesom@gmail.com
}

\begin{abstract}
Digital Elevation Model (DEM) and its resulting parameters are essential terrain related information. DEM and the extracted information (slope, aspect, roughness etc.) have been identified as one of the most important and fundamental variables to various streams of engineering and planning designs which are the hall marks of development all over the world. Thus, to delineate the major surface and subsurface structures for evaluating the Planning framework for the Federal Capital City of Nigeria, analyzing the effects of terrain configuration of Shuttle Radar Topographic Mission (SRTMV3) and ALOS PALSAR DEM data is very crucial. Hence this paper aimed at examining the effects of terrain configuration of Shuttle Radar Topographic Mission (SRTMV3) and ALOS PALSAR DEM. The methodology involved data acquisition of ALOS PALSAR, SRTMV3 and Ortho DEMs, after which the ALOS PALSAR and SRTMV3 DEMs were resampled to $10 \mathrm{~m}$ of the Ortho DEM, image classification and then an assessment of the impact of terrain configuration on DEM performance with horizontal profiles was carried out. The results revealed that SRTMV3 v3 performed better with close resemblance with the Ortho DEM on flat and undulating terrain while it underestimated the rolling terrain and overestimated the hilly and mountainous terrain. ALOS PALSAR DEM when compared against the Ortho DEM grossly overestimated all the terrain configuration in the study area. In all, the overall performance of SRTMV3 v3 had a close resemblance in performance to that of the Ortho DEM, while ALOS PALSAR had a significant difference in performance. It was therefore recommended that SRTMV3 v3 should be used as an alternative DEM source where high-resolution elevation data are not readily available.
\end{abstract}

Keywords: ALOS PALSAR, Digital Elevation Model, SRTM, Terrain modelling.

DOI: $10.7176 / \mathrm{JEES} / 10-6-14$

Publication date:June $30^{\text {th }} 2020$

\section{Introduction}

From time past, the major source of elevation data has been the traditional ground survey and photogrammetric methods. However, these two methods are time consuming, laborious, expensive and largely dependent on weather conditions (Jensen 2009). Also, the design and implementation of the City was based on the 1963 Topographic maps of 1:50,000 and thus there is the urgent need for map updates.

Following the above, it became necessary to source for economically pragmatic alternative means of generating elevational information; and expedient to use one of freest alternative source of obtaining elevation data for topographic mapping of urban and rural areas for various applications. This is because where local topographical data is unavailable, incomplete or outdated, DEMs from remotely sensed data such as SRTM and ALOS PALSAR GDEM can be the main source of information (Nwilo, 2012). The SRTM datasets has the capacity to produce elevational information which can be used for applications such as hydrology and watershed dynamics, erosion modelling, flooding risks modelling, planning and engineering designs etc. Kolecka \& Kozak (2014).

The validation of STRM DEM data carried out in the North Central Part of Nigeria by Ojigi \& Dang (2010) in Lokoja, Kogi state was based on heights obtained from topographic maps, This study did not reflect the Land cover types, the hydrologic model of the terrain, the difference in the vertical datum of the Topographic Map and that of the SRTM. Another study carried by Isioye \& Obafaro (2016) validated a few datasets in Zaria and its environs. The lack of available records that collaborate previous study on the accuracy assessment of the SRTM and ALOS PALSAR data in most part of the Federal Capital Territory and the need to use the SRTM and ALOS PALSAR as an alternative source of elevation data made it become necessary to validate the quality of data generated from the SRTM global digital elevation model over FCT which is the study area of interest. Furthermore, the creation of large-scale digital topographic databases of urban areas provides, a rich source of basic data that could be used in a variety of applications thus professionals such as urban planners and engineers can use such data for both analytical and management-oriented applications. Accordingly, in the developing world, Geographic Information (GI) is increasingly accessible to mapping agencies and local government agencies, opening 
possibilities to improve the supply of data for GI applications in urban management.

In the Capital City of Nigeria, where there are so many developmental activities going; the urban planners, Engineers and other environmental related professionals could use the SRTM and ALOS PALSAR DEM for analysis and management in the area of urban design and planning, environmental monitoring, and hydrology, hence the need to evaluate the quality of the SRTM and ALOS PALSAR dataset before use. Even though it might appear that these DEMs provide clear and detailed interpretations of topography and terrain surfaces, these representations can bait users of the datasets into a false sense of security regarding the accuracy and precision of the data. Hence, it is important to validate the resulting dataset from the SRTM and ALOS PALSAR DEM because global datasets are subject to errors due to the approach used to extract the elevation information and the processing procedures such as interpolation adopted (Nikolakopoulos, Kamaratakis \& Chrysoulakis, 2006).

\subsection{Study Area}

The study area for this study is Abuja Federal Capital Territory. Abuja is located in the heart of the country. The FCT stretches across approximately 8,000 square kilometres. With a geographic location of latitude $7^{0} 25^{\prime} \mathrm{N}$ and $9^{0} 20^{\prime}$ North and longitude $5^{0} 45^{\prime} \mathrm{E}$ and $7^{0} 39^{\prime}$ East, the FCT is bordered on the north by Kaduna, on the west by Niger, on the east by Plateau, and on the South-west by Kogi. The geographic location of Abuja is shown in figure 1.1. It comprises six Local councils, namely Abaji, Bwari, Kuje, Gwagwalada, Kwali and Abuja Municipal Area Council (AMAC) which is the metropolitan city of Abuja

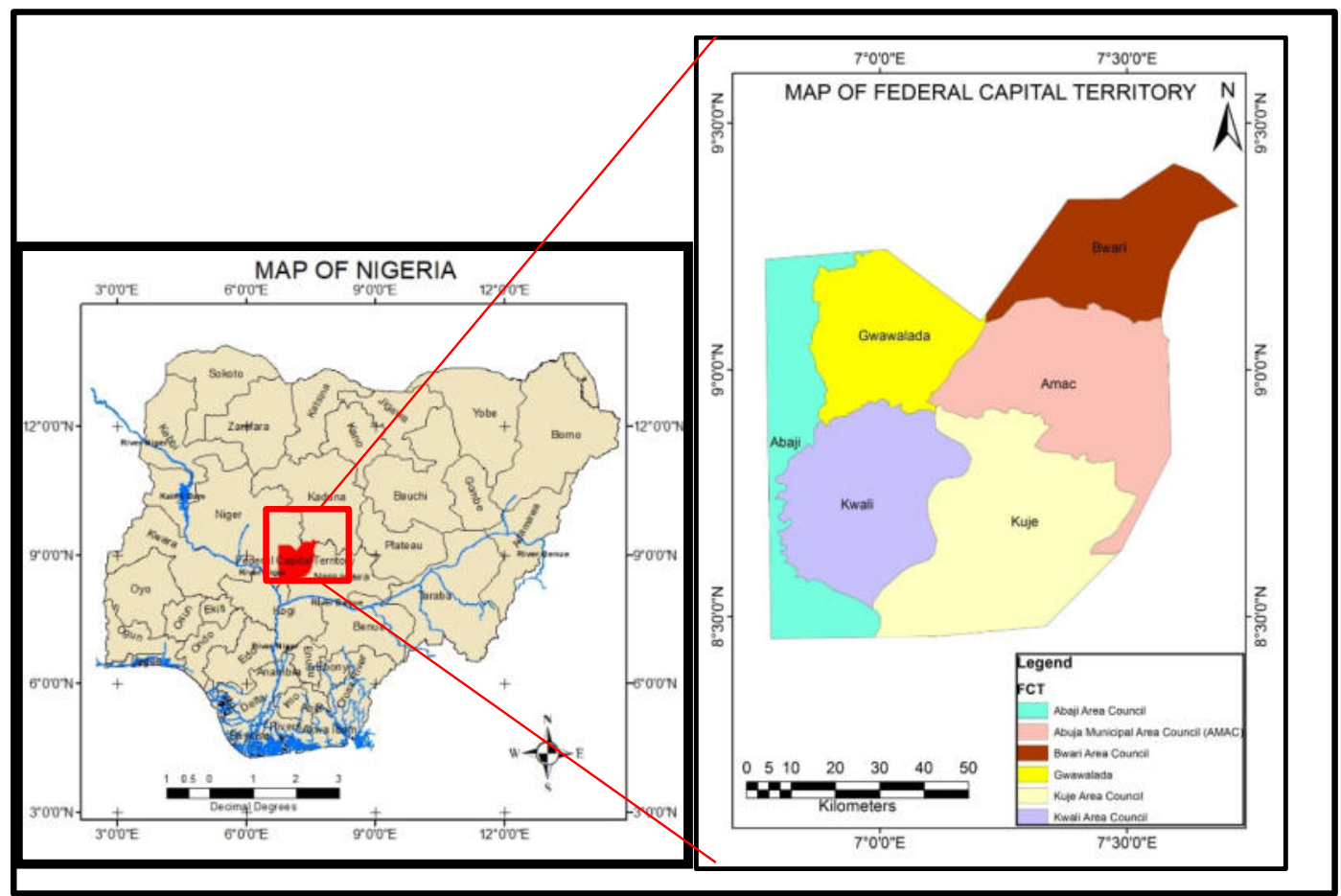

Fig 1.1: Map of Federal Capital Territory showing its position in Nigeria

\section{Materials and Methods}

SRTMV3 and ALOS PALSAR imagery were downloaded from http://earthexplorer.usgs.gov and https://vertex.daac.asf.alaska.edu/ respectively. The $10 \mathrm{~m}$ spatial resolution Ortho DEM produced from aerial survey of FCT in 2010, was acquired from the Department of Survey and Mapping, Federal Capital Development Agency (FCDA) Abuja. The SRTM and ALOS PALSAR were resampled to $10 \mathrm{~m}$ resolution to achieve data conformity with that of the ortho DEM. After which ground validation of the Ortho DEM was done in order to ascertain the fitness of the ortho DEM in validating SRTM and ALOS PALSAR over FCT Nigeria.

To determine the effect of terrain configuration on SRTMV3 and ALOS PALSAR DEM, SRTMV3, ALOS PALSAR and Ortho DEM were reclassified into five classes of terrain configuration based on the Food and Agricultural Organization (FAO) categories of classification of slopes. According to Daffi and Otun (2010) and Ejikeme et al (2018), the five terrain classes were: $1-40 \mathrm{~m}=$ flat, $40-80 \mathrm{~m}=$ undulating, $80-120 \mathrm{~m}=$ rolling, 120 - 
$150 \mathrm{~m}=$ hilly and $150-180 \mathrm{~m}=$ mountainous. The five classes were converted to polygon and elevation points that fell within each of the terrain classes were extracted for the different elevation datasets and then, profiles were created for each of the terrain class over the three Dems

\section{Results}

\subsection{Ground Validation of Ortho DEM using FCT Ground control points}

The choice of using Ortho DEM as a reference for validating SRTMv3 and ALOS PALSAR was because the Ortho DEM was the closest source for high resolution reference data that covered the study area in its entirety. The Ortho DEM was obtained as a result of the aerial survey carried out over Abuja, FCT and has a resolution of $10 \mathrm{~m}$. which makes it better than SRTMv3 and ALOS PALSAR in terms of resolution and accuracy. Hence the decision, but in order to use the ortho DEM in validation of SRTMV3 and ALOS PALSAR over FCT, the ortho DEM had to be validated first using ground control points on ground, the elevation points obtained from the Ortho DEM was compared with the elevation points pick from ground, the results are illustrated in figure 3.1.

\section{Correlation between GCPs and Ortho DEM Points}

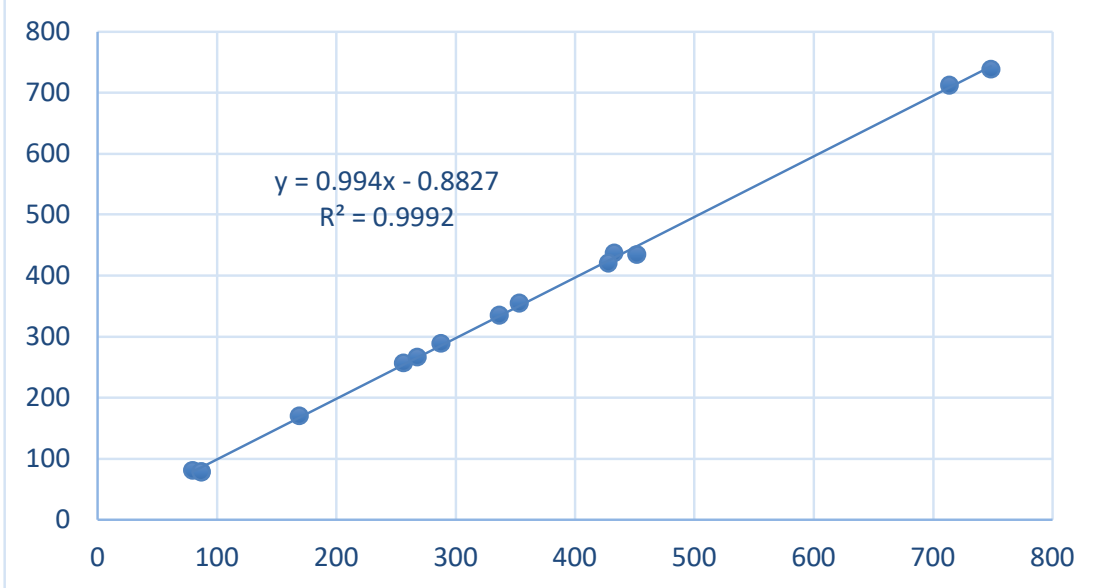

Figure 3.1: Correlation between GCP and Ortho DEM Points

From figure 3.1, the correlation results gave a value of 0.99 which indicates a strong positive relationship between the ground control points and the elevation points from the ortho DEM. This means that the ortho DEM is a good fit and represents closely the elevation values on ground, hence it can be used to validate SRTMVv3 and ALOS PALSAR DEM over FCT.

\subsection{Effect of terrain configuration on the performance of SRTMV3 and ALOS PALSAR DEM}

To determine the effect of terrain configuration on the performance of SRTMv3 and ALOS PALSAR, the DEMs were reclassified into five terrain classes. The result of the terrain classification is shown in fig 3.2. 


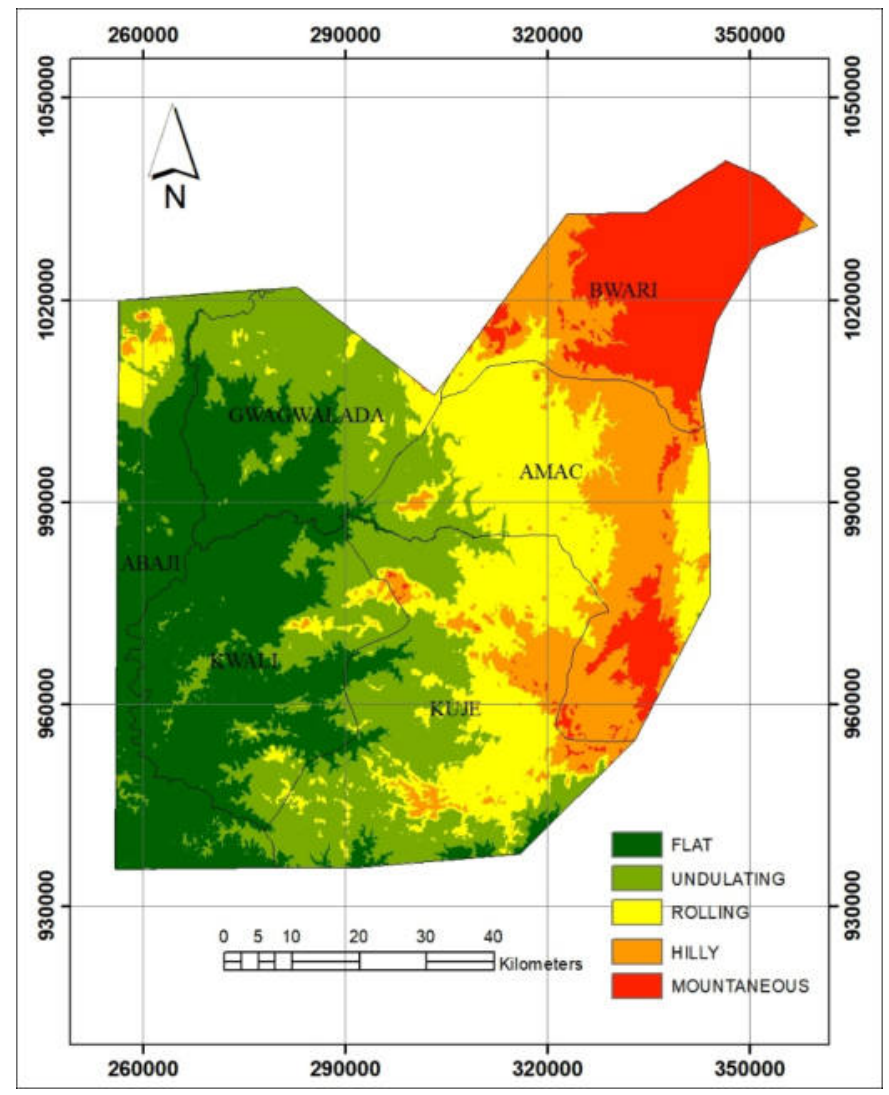

Figure 3.2: Result of Terrain Classification

Cross section lines were drawn on each terrain classes and to obtain horizontal profiles for the terrain class. Fig 3.3 - 3.7 shows the horizontal profiles obtained for each of the terrain class for the SRTMv3, ALOS PALSAR and the Ortho DEM. Pearson's correlation coefficient test was used to ascertain the relationship between the elevation values gotten from SRTMv3 and ALOS PALSAR against the Ortho DEM at different terrain configurations. The range of the correlation coefficients is from -1 to +1 . If there is a strong positive linear relationship between the variables, the value of correlation coefficient ( $r$ ) will be close to +1 . If there is a strong negative linear relationship between the variables, the value of $r$ will be close to -1 . When there is no linear relationship between the variables or only a weak relationship, the value of $r$ will be close to 0 .

From the mountainous terrain profile figure 4.3 and table 3.4, it can be seen that SRTMv3 profile with a mean elevation of $734 \mathrm{~m}$ overestimated the mountainous terrain by $9 \mathrm{~m}$ while ALOS PALSAR profile with a mean elevation of $756 \mathrm{~m}$ overestimated the mountainous terrain by $31 \mathrm{~m}$ in comparison to the Ortho DEM with mean elevation of $725 \mathrm{~m}$. The profile of SRTMv3 compares favorably to the Ortho DEM as indicated in table 4.5 with a correlation coefficient of 0.903 , which indicates a strong linear relationship, while ALOS PALSAR compared relatively below SRTMv3 in comparison to the Ortho DEM with a correlation coefficient of 0.602. Thus, SRTMv3 performed better than ALOS PALSAR on mountainous terrain in the study area. 

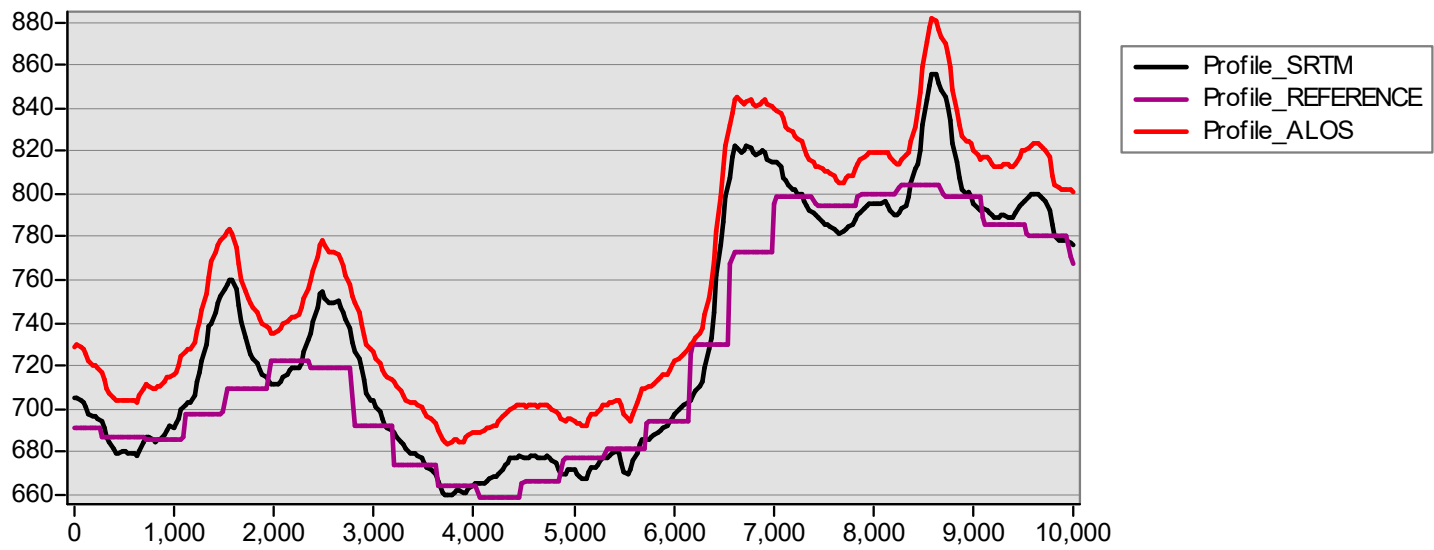

Figure 3.3: Mountainous Terrain Profile

Table 3.4: Profile characteristics for Mountainous Terrain

\begin{tabular}{|c|c|c|c|}
\hline Mountainous Terrain & Minimum Height $(\mathrm{m})$ & Maximum Height $(\mathrm{m})$ & Mean Height $(\mathrm{m})$ \\
\hline Ortho DEM & 658 & 804 & 725 \\
\hline SRTMV3V3 & 660 & 861 & 734 \\
\hline ALOS PALSAR & 684 & 879 & 756 \\
\hline
\end{tabular}

The hilly terrain profile in figure 3.4 and table 3.5, indicated that SRTMv3 profile with a mean elevation of $504 \mathrm{~m}$ overestimated the hilly terrain by $15 \mathrm{~m}$ while ALOS PALSAR profile with a mean elevation of $524 \mathrm{~m}$ overestimated the hilly terrain by $35 \mathrm{~m}$ in comparison to the Ortho DEM had a mean elevation of $489 \mathrm{~m}$. The profile of SRTMv3 compares favorably to the Ortho DEM as indicated in table 4.7 with a correlation coefficient of 0.789 , which indicates a good linear relationship, while ALOS PALSAR compared relatively below SRTMv3 in comparison to the Ortho DEM with a correlation coefficient of 0.642. Thus, SRTMv3 performed better than ALOS PALSAR on hilly terrain in the study area although the disparity between SRTMv3 and Ortho DEM is $15 \mathrm{~m}$.

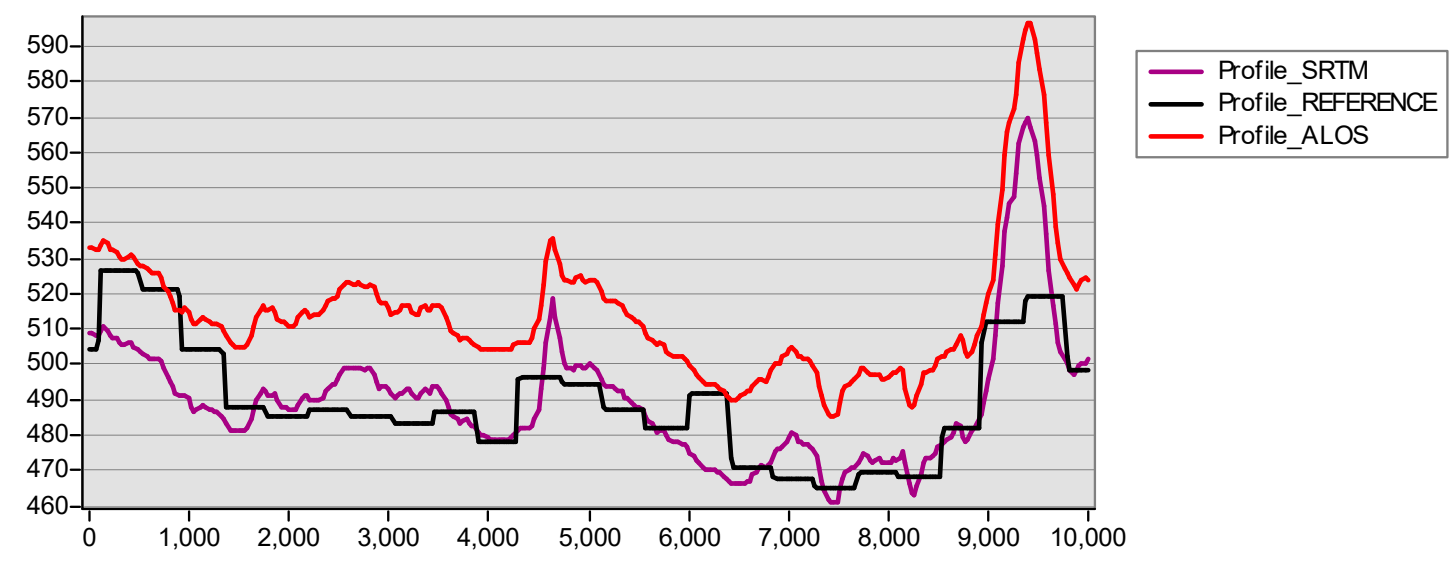

Figure 3.4: Hilly Terrain Profile

Table 3.5: Profile characteristics for Hilly Terrain

\begin{tabular}{|c|c|c|c|}
\hline Hilly Terrain & Minimum Height (m) & Maximum Height (m) & Mean Height (m) \\
\hline Ortho DEM & 465 & 526 & 489 \\
\hline SRTMv3 & 461 & 573 & 504 \\
\hline ALOS PALSAR & 485 & 595 & 524 \\
\hline
\end{tabular}


From the rolling terrain profile in figure 3.5 and table 3.6, it can be seen that SRTMv3 profile with a mean elevation of $369 \mathrm{~m}$ underestimated the rolling terrain by $6 \mathrm{~m}$ while ALOS PALSAR profile with a mean elevation of $392 \mathrm{~m}$ overestimated the hilly terrain by $17 \mathrm{~m}$ in comparison to the Ortho DEM which had mean elevation of $375 \mathrm{~m}$. The profile of SRTMv3 compares favorably to the Ortho DEM as indicated in table 4.9 with a correlation coefficient of 0.697 , which still indicates a good relationship, while ALOS PALSAR compared relatively below SRTMv3 in comparison to the Ortho DEM with a correlation coefficient of 0.461 . Thus, SRTMv3 performed better than ALOS PALSAR on rolling terrain in the study area.

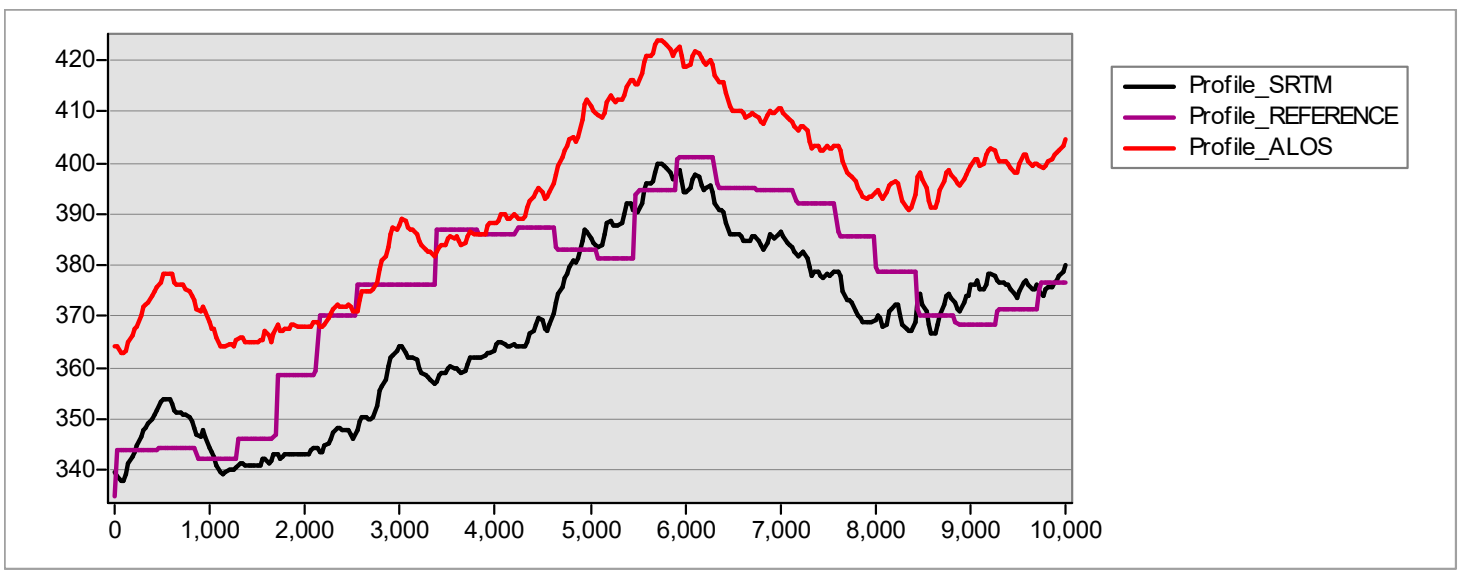

Figure 3.5 Rolling Terrain Profile

Table 3.6: Profile characteristics for Rolling Terrain

\begin{tabular}{|c|c|c|c|}
\hline Rolling Terrain & Minimum Height $(\mathrm{m})$ & Maximum Height $(\mathrm{m})$ & Mean Height $(\mathrm{m})$ \\
\hline Ortho DEM & 333 & 401 & 375 \\
\hline SRTMv3 & 339 & 400 & 369 \\
\hline ALOS PALSAR & 363 & 424 & 392 \\
\hline
\end{tabular}

From the undulating terrain profile in fig 3.6 and table 3.7, it can be seen that SRTMv3 profile with a mean elevation of $247 \mathrm{~m}$ overestimated the undulating terrain by $1 \mathrm{~m}$ while ALOS PALSAR profile with a mean elevation of $269 \mathrm{~m}$ overestimated the hilly terrain by $22 \mathrm{~m}$ in comparison to the Ortho DEM which had a mean elevation of $247 \mathrm{~m}$. The profile of SRTMv3 compares favorably to the Ortho DEM as indicated in table 4.11 with a correlation coefficient of 0.976 , which still indicates an excellent relationship, while ALOS PALSAR compared relatively below SRTMv3 in comparison to the Ortho DEM with a correlation coefficient of 0.732 which also indicates a good relationship. Thus, SRTMv3 performed better than ALOS PALSAR on undulating terrain in the study area as it bears a close terrain resemblance to the Ortho DEM profile.

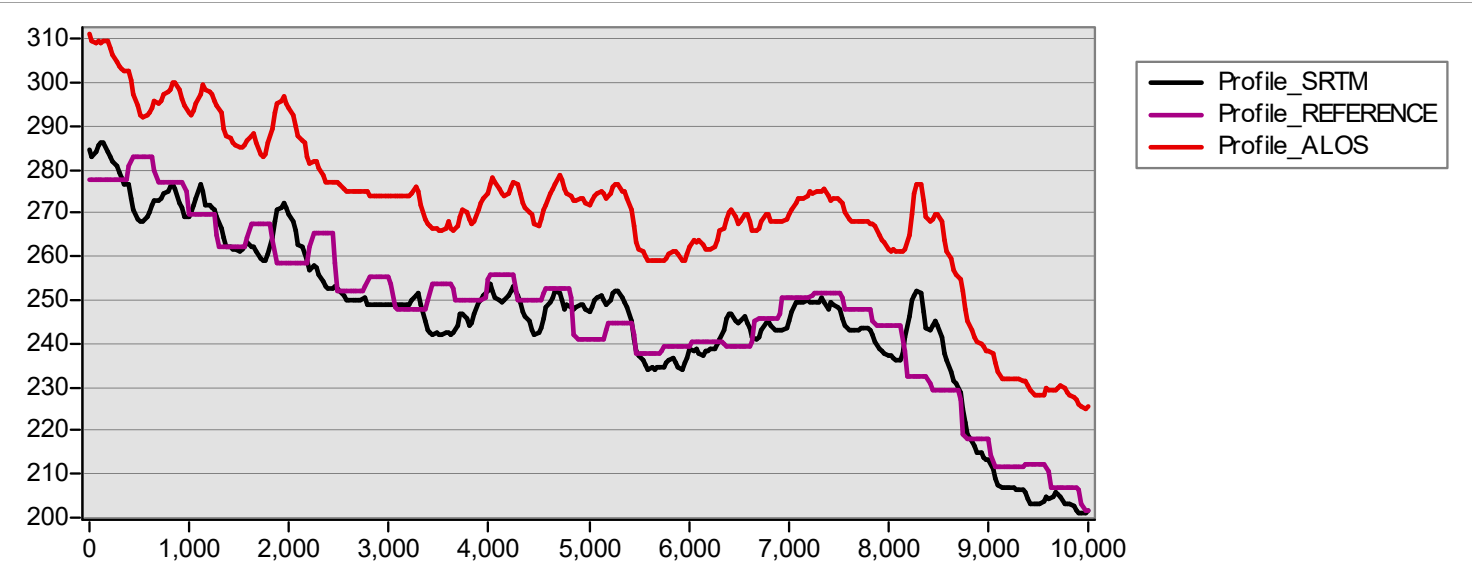

Figure 3.6: Undulating Terrain Profile 
Table 3.7: Profile characteristics for Undulating Terrain

\begin{tabular}{|c|c|c|c|}
\hline Undulating Terrain & Minimum Height $(\mathrm{m})$ & Maximum Height $(\mathrm{m})$ & Mean Height $(\mathrm{m})$ \\
\hline Ortho DEM & 202 & 283 & 247 \\
\hline SRTMV3V3 & 201 & 287 & 246 \\
\hline ALOS PALSAR & 225 & 312 & 269 \\
\hline
\end{tabular}

From the flat terrain profile in fig 3.7 and table 3.8, it can be seen that SRTMv3 profile with a mean elevation of $120 \mathrm{~m}$ represented the flat terrain closely, while ALOS PALSAR profile with a mean elevation of $145 \mathrm{~m}$ overestimated the flat terrain by $25 \mathrm{~m}$ in comparison to the Ortho DEM which had a mean elevation of $120 \mathrm{~m}$. The profile of SRTMv3 compares favorably to the Ortho DEM as indicated in table 4.13 with a correlation coefficient of 0.983 , which still indicates an excellent relationship, while ALOS PALSAR compared relatively below SRTMv3 in comparison to the Ortho DEM with a correlation coefficient of 0.311. Thus, SRTMv3 performed better than ALOS PALSAR on flat terrain in the study area as it also bears a close terrain resemblance to the Ortho DEM profile.

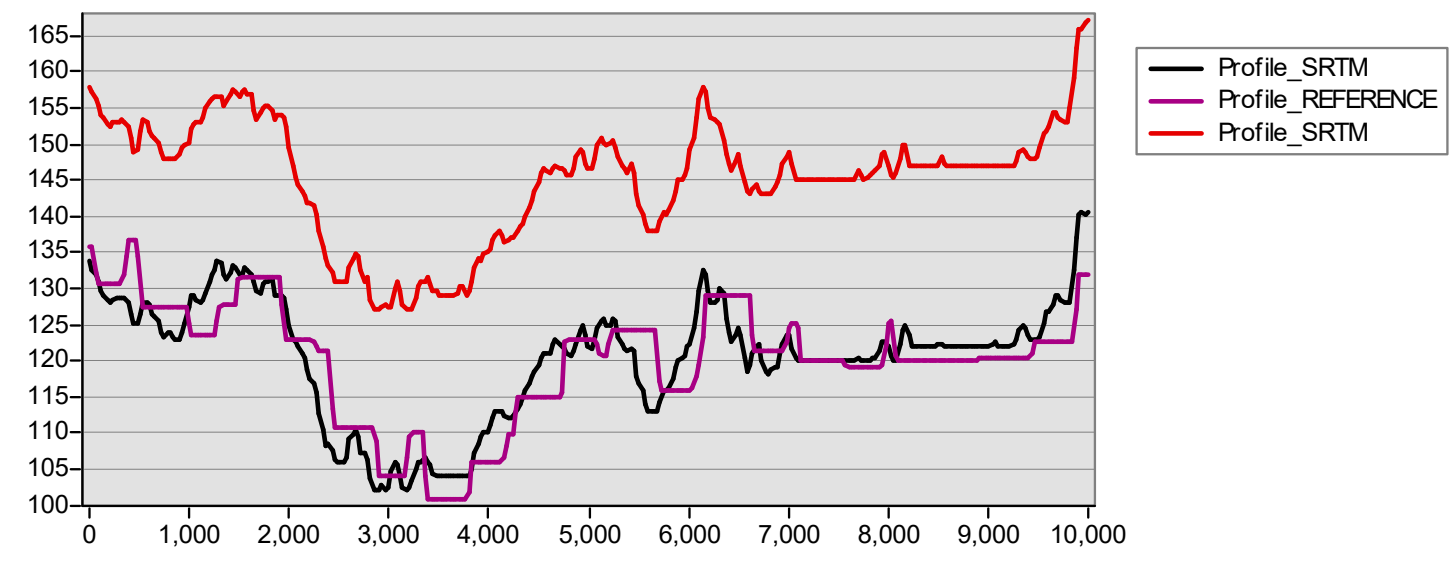

Figure 3.7 Flat Terrain Profile

Table 3.8: Profile characteristics for Flat Terrain

\begin{tabular}{|c|c|c|c|}
\hline Flat Terrain & Minimum Height $(\mathrm{m})$ & Maximum Height $(\mathrm{m})$ & Mean Height $(\mathrm{m})$ \\
\hline Ortho DEM & 101 & 136 & 120 \\
\hline SRTM & 100 & 142 & 120 \\
\hline ALOS PALSAR & 126 & 167 & 145 \\
\hline
\end{tabular}

In all, SRTMv3 performed better with close resemblance with the Ortho DEM at flat and undulating terrain while it underestimated the rolling terrain and overestimated the hilly and mountainous terrain. ALOS PALSAR DEM when compared against the Ortho DEM grossly overestimated all the terrain configuration in the study area.

\section{Conclusion and Recommendations}

SRTMv3 and ALOS PALSAR DEM provides alternative source of elevation data needed for topographic and hydrologic applications in the study area. this study has successfully evaluated their performance and Demonstrated that the performance obtained from SRTMv3 and ALOS PALSAR are not the same. In the study area, FCT, SRTMv3 is proven to be the best alternative to elevation data over ALOS PALSAR. its overall performance showed that it best represented the terrain over the study area. With the non-availability of up-to-date topographic and hydrologic maps of the study area, this study has further Demonstrated that global elevation datasets, particularly SRTMv3, have a good potential for topographical and hydrological modeling. The contour map produced from SRTMv3 can be used effectively in topographic mapping at scale 1:50000 and smaller scales. Based on the result of the findings from this study, the following recommendations were made:

1. From the results achieved in the study, SRTMv3 is recommended for use in topographic and hydrological modeling in FCT, Nigeria where high-resolution elevation data are not readily available.

2. It is recommended that caution should be applied when using ALOS PALSAR Data in FCT as it generally tends to overestimate elevation values of the terrain 
3. Also, it is recommended that caution be applied when using SRTMv3 data in hilly terrain in FCT as it overestimated the elevation values as indicated by the study results.

\section{References}

Daffi, R.E \& Otun, J.A (2010). Delineation of Floodplains of DEP River Basin using Remote sensing and Geographic Information System. In the Proceedings of the Nigerian Union of Planetary and Radio Sciences (NUPRS) Conference. Lagos: BPrint Publishing.

Ejikeme, J.O, Igbokwe, J.I., Ojiako, J.C. \& Umenweke D.O. (2018) Assessment of The Impact of Terrain Configuration and Landuse/ Landcover on the Performance of SRTM, Aster Version1 And Version2 Gdems: A Case Study of Onitsha and Environs, Anambra State, Nigeria " IOSR Journal of Environmental Science, Toxicology and Food Technology (IOSR-JESTFT) 12.2: 40-49

Isioye, O. A., \& Obafaro, E. O. (2016). Shuttle Radar Topography Mission (SRTM) Elevation Data: A Contemporary Global Elevation Model for describing the topography in Zaria and its environs. Ife Research Publications in Geography, 9(1), 221-245.

Jensen, J. R. (2009). Remote sensing of the environment: An earth resource perspective 2/e. Pearson Education India.

Kolecka, N., \& Kozak, J. (2014). Assessment of the accuracy of SRTM C-and X-Band high mountain elevation data: A case study of the Polish Tatra Mountains. Pure \& Applied Geophysics, 171(6), 897.

Nikolakopoulos, K. G., Kamaratakis, E. K., \& Chrysoulakis, N. (2006). SRTM vs ASTER elevation products. Comparison for two regions in Crete, Greece. International Journal of remote sensing, 27(21), 4819-4838.

Nwilo, P.C (2012). Surveying Practice in the Nigerian Contemporary Society. Keynote Address Presented on the Occasion of the Official Opening and Dedication of "Surveyors House" of Nigerian Institution of Surveyors (NIS), Enugu State Branch.

Ojigi, M.L. and Dang, B.A. (2010). 3-Dimensional Data Validation of Shuttle Radar Topographic Mission (SRTM) in Lokoja Area of Nigeria. Nigerian Journal of Surveying and Geoinformatics, 3(1), pp. 67-85. 